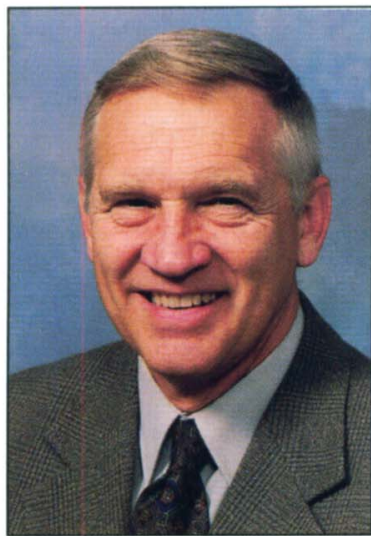

\title{
Veterinary medicine: Mandates and missions for the 21st century
}

\author{
Bennie I. Osburn, Dean \\ UC Davis School of Veterinary Medicine
}

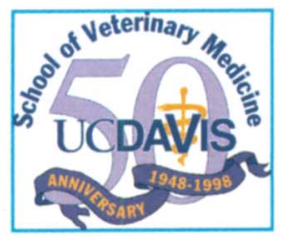

alifornia, the most populous state in the nation, is also the state with the fewest veterinarians per capita - only 17 per 100,000 residents, compared to the national average of 21 veterinarians per 100,000 citizens. Even the latter is inadequate to meet society's demand. At the 1997 Western Veterinary Conference, there were five jobs for every applicant.

The current shortage of veterinarians occurs as the need for their expertise is rising. Consolidation of food production industries, worldwide distribution of products, and potential risks from imported foods create demand for food safety assurance at every stage of production. As incidents of foodborne and waterborne illness increase, veterinarians must solve new problems relating to Salmonella, Cryptosporidium parvum, Escherichia coli $\mathrm{O} 157: \mathrm{H7}$, and other emerging, virulent forms of disease.

UC Davis' School of Veterinary Medicine, the state's only veterinary school, produces about 108 veterinarians a year. With California's population increasing $1.8 \%$ a year, the School should be graduating 60 more veterinarians annually just to maintain the current ratio of 17 to 100,000 residents.

The School cannot currently meet this demand. While enrollment is up from 108 to 122 students for 1998-99, we cannot expand further until more faculty are hired.

We must also construct more classrooms and laboratories. Haring Hall, dedicated in 1950, was designed to serve roughly 50 students per class. The program outgrew the facility within 10 years. At the teaching hospital, built in 1970, faculty treat as many patients in one month as they once did in an entire year. Despite planning efforts dating back more than 20 years, funds to expand facilities have not materialized.

The School and state legislators have already taken the first steps to address these issues. Recently, the Legislature and Governor approved a $\$ 2.5$ million annual university budget augmentation. These funds will help us begin to address the veterinarian shortage by further increasing class size, which we hope to expand to 131 students by 1999 . Twelve new faculty positions can be filled. We will add 30 residents to help meet the demand for specialized veterinary care services. The School will establish a long-awaited program to better serve Southern California.

The School has also launched a $\$ 50$ million capital campaign to raise money for new classrooms, teaching laboratories and clinical facilities. Endowments funded through the campaign will provide ongoing private support for scholarships, faculty positions and research programs.

These new initiatives cannot start too soon. This summer the American Veterinary Medical Association recommended that the School be placed on "limited" accreditation status based on two areas of weakness: finances and facilities. The School fully meets nine of eleven essential requirements: faculty, research, curriculum, clinical resources, library resources, students, admissions, continuing education, and organization. The School is recognized by the AVMA for outstanding performance in several areas, especially curriculum, research and continuing education.

The School has filed an appeal: The institution fulfills all program objectives, and finances and facilities meet established standards. The appeal decision will be made in November.

Program activities remain fully functional. Students still graduate from a nationally accredited program and qualify for licensing exams. However, because our reputation may be affected, we may find it more difficult to recruit top students and faculty, maintain donor support, and fully serve our missions in the future. If the AVMA decides upon limited accreditation, the School, University, state and animal-owning public must pull together to solve these financial and facilities concerns.

Veterinary education is a wise investment. Millions of Californians rely on veterinarians to care for their companion animals -7.6 million cats, 6.1 million dogs, 640,000 horses, and thousands of exotic pets.

Veterinarians also protect the health and well-being of food animals in California's $\$ 26.8$ billion agricultural economy and design food safety strategies to protect consumers. (California is the nation's leading dairy producer as well as beef exporter.) The School works with the California Department of Food and Agriculture in a statewide program to test milk samples, diagnose disease in food animals, and report and consult on food animal illnesses.

Veterinarians advance the stewardship of zoo animals, wildlife and the environment, addressing interface issues among agriculture, the environment and urban areas.

The public receives dividends from comparative medical research into diseases which jump species barriers from animals to humans. These include traditional threats such as rabies, emerging problems such as Lyme disease and AIDS, and food- or waterborne diseases mentioned above.

The School urges the involvement of agricultural and business leaders, government representatives, and the general public in planning veterinary education for the next generation. UC Davis has gladly met the state's complex mandates in veterinary science and teaching for the past 50 years. With the help of all Californians, the School of Veterinary Medicine will continue to provide the highly trained, dedicated veterinarians needed in many realms. 